\title{
Pregnancy Wastage Due to Fetal Congenital Malformations
}

\author{
Vijayata SANGWAN', Shivani KHANDELWAL ${ }^{1}$, Rajiv MAHENDRU1, Pinkey LAKRA ${ }^{1}$, Sunita SIWACH \\ Haryana, India
}

\begin{abstract}
OBJECTIVES: To study the pattern of various congenital anomalies in rural Haryana.

STUDY DESIGN: This was a retrospective study conducted over 1 and $1 / 2$ years (from January 2015 to June 2016) in a tertiary care center in Haryana, India.

RESULTS: Out of 11,178 births, 227 babies had gross congenital malformations $2.03 \%$. In literature, the most common birth defect reported in western countries is cardiovascular anomalies while in India and eastern countries, it's the neural tube defect. In our study also, neural tube defects were the most common congenital anomalies accounting for $64.31 \%$ of total anomalies. They were more common in unbooked patients $(70 \%)$ and the rural population. So, the main cause appears to be a lack of awareness and illiteracy.
\end{abstract}

CONCLUSION: There is a need for increased awareness and folic acid supplementation routinely in the periconceptional period to decrease the incidence of congenital anomalies.

Keywords: Congenital malformations, Folic acid, Pregnancy wastage

Gynecol Obstet Reprod Med 2021;27(2):94-98

\section{Introduction}

A congenital malformation is defined as any irreversible abnormality in the physical or anatomical or functional form existing in a child before birth. They are of two types-major and minor. Major anomalies are those which create a significant medical problem or require specific management. Minor anomalies are relatively minor physical abnormalities. These anomalies represent a global burden and are a public health challenge. The common causes are genetic i.e., chromosomal anomalies, environmental such as chemical and radiation exposure and teratogenic drugs, dietary deficiencies, and medical disorders like diabetes and hypothyroidism. Congenital malformations are common in India, as it is a developing country. Seventy percent of the Indian population lives in

${ }^{1}$ Department of Obstetrics and Gynecology, BPSGMC, Khanpur, Sonepat, Haryana, India

Address of Correspondence: Shivani Khandelwal

B 21, Medical Campus, BPSGMC, Khanpur,

Sonepat, Haryana-131305-India

Contact No.:918607604886

drshivani68@gmail.com

Submitted for Publication: 06.04.2020 Revised for: Publication: 27.04.2020

Accepted for Publication: 06.05.2020 Online Published: 02.08.2021

ORCID IDs of the authors: VS: 0000-0001-7775-6293

SK: 0000-0002-6730-8785, RM: $0000-0003-1916-7962$

PL: 0000-0002-9252-6864, SS: 0000-0003-4133-7446

\begin{tabular}{c|c}
\hline $\begin{array}{c}\text { Quick Response Code: } \\
\text { nat }\end{array}$ & Access this article online \\
\cline { 2 - 2 } & $\begin{array}{l}\text { Website: www.gorm.com.tr } \\
\text { e- mail: info@gorm.com.tr }\end{array}$ \\
\cline { 2 - 2 } & DOI:10.21613/GORM.2020.1095 \\
\hline
\end{tabular}

How to cite this article: Sangwan V. Khandelwal S. Mahendru R. Lakra P. Siwach S. Pregnancy Wastage Due to Fetal Congenital Malformations. Gynecol Obstet Reprod Med 2021;27(2):94-98 rural India. Due to lower literacy and lack of education, people do not take adequate antenatal care which significantly contributes to congenital anomalies. They go to the hospital only for delivery and forego first-trimester antenatal visits, hence there is no folic acid intake leading to anomalies. Again, the villages are agriculture-based so pesticides play an important role in causing the anomalies. 2-3\% of newborns have recognized structural defects (1). Annually 3.3 million deaths are associated with birth defects, mainly major anomalies (2). An estimated 30,3000 newborns die within 4 weeks of birth every year worldwide due to congenital anomalies (3). Interestingly prevalence and the pattern of congenital anomalies vary over time and geographical location and hence we decided to do study in our hospital.

\section{Material and Method}

It is a retrospective study conducted in the Obstetrics and Gynecology Department of BPSGMC(W), Khanpur Kalan, Sonepat, over a period of one and a half year from $1^{\text {st }}$ January 2015 to $30^{\text {th }}$ June 2016 , which is a tertiary care center in rural Haryana, enrolling all babies having congenital anomalies irrespective of gestational age that comprised 11,178 deliveries. Maternal age, gestational age, birth order, maternal illness, drug or radiation exposure, medical history, family history, consanguinity and associated obstetric complications, antenatal radiological findings if available were included in the study. After birth baby sex, weight, and clinical details were recorded by a skilled pediatrician. If needed ultrasonography was done after birth to confirm internal anomalies. High-risk neonates were kept under observation. The outcome of babies 
was recorded during the hospital stay. No fetal autopsy was done. Data were analyzed with SPSS software.

It is a retrospective data analysis. This study was conducted in accordance with the Declaration of Helsinki. There is a provision of informed written consent in our medical records regarding utilization of data for academic purpose and therefore we took it for analysis after ethical clearance from our institutional ethical committee vides letter no. BPSGMCW/RC 487/IEC/19 dated 13.11.19.

\section{Results}

The total number of births in 1 and $1 / 2$ year were 11,178 .
The total number of gross congenital malformation (GCMF) babies in this period were 227 and the incidence of GCMF babies in this period was $2.03 \%$. The most common anomalies were CNS anomalies i.e., $64.31 \%$ followed by GIT as shown in table I. The malformations were more common in unbooked patients, from a rural background, and of lower literacy levels as depicted in table II. Female fetuses and babies had more (53.7\%) anomalies than their male counterpart as shown in table III. It also depicts that out of 227 deliveries 150 fetuses were dead and 77 were alive. The pattern of GCMF according to sex distribution is demonstrated in table IV. Table $\mathrm{V}$ tells about the possible etiologies of GCMF in our study.

Table I: Distribution of malformations according to the organ system involved

\begin{tabular}{lccc}
\hline Organ-specific gross congenital malformation & number & $\begin{array}{c}\% \text { of total } \\
\text { malformations }\end{array}$ & $\begin{array}{c}\text { No. of incompatible fetuses with life } \\
\text { or stillborn fetuses }\end{array}$ \\
\hline Central nervous system & 146 & 64.31 & $113(77.9 \%)$ \\
Gastrointestinal tract & 33 & 14.53 & $13(39.39 \%)$ \\
Genitourinary system & 18 & 7.92 & $12(66.66 \%)$ \\
Musculoskeletal system & 10 & 4.40 & $00(00 \%)$ \\
Cardiovascular system & 05 & 2.20 & $02(40 \%)$ \\
Respiratory system & 04 & 1.76 & $02(50 \%)$ \\
Special sensory as cleft lip and palate or anotia & 04 & 1.76 & $01(25 \%)$ \\
Multiple sequences (syndromes) & 07 & 3.08 & $07(100 \%)$
\end{tabular}

Table II: Maternal demographic profile of gross congenital malformation babies

\begin{tabular}{|c|c|c|}
\hline \multirow[t]{2}{*}{ Status of ANC visits } & Booked & $30 \%$ \\
\hline & Unbooked & $70 \%$ \\
\hline \multirow[t]{2}{*}{ Residence } & Urban & $36 \%$ \\
\hline & Rural & $64 \%$ \\
\hline \multirow[t]{3}{*}{ Education status } & Illiterate & $39 \%$ \\
\hline & $5-12^{\text {th }}$ & $49 \%$ \\
\hline & $>=$ graduate & $12 \%$ \\
\hline \multirow[t]{3}{*}{ Age (years) } & 19 y or less & $3.08 \%$ \\
\hline & $20-29 y$ & $68.28 \%$ \\
\hline & 30 y or more & $28.63 \%$ \\
\hline \multirow[t]{3}{*}{ Trimester } & $1^{\text {st }}$ & $8 \%$ \\
\hline & $2^{\text {nd }}$ & $33 \%$ \\
\hline & $3^{\text {rd }}$ & $59 \%$ \\
\hline
\end{tabular}

Table III: Features of gross congenital malformation babies

\begin{tabular}{lcc}
\hline Sex of gross congenital malformation babies & No. & $\%$ \\
Male & 104 & $45.8 \%$ \\
Female & 122 & $53.7 \%$ \\
Ambiguous & 01 & $0.44 \%$ \\
Incidence of gross congenital malformation in singleton and twin pregnancy & & $2.01 \%$ \\
Singleton & $5.5 \%$ & \\
Twin & & $66.07 \%$ \\
Survival outcome & 150 & $33.92 \%$ \\
Exitus & 77 & \\
Alive & & \\
\hline
\end{tabular}


Table IV: Pattern of gross congenital malformation babies according to sex

\begin{tabular}{llc}
\hline Organ-specific gross congenital malformation & Male & Female \\
\hline Central nervous system & 59 & 87 \\
Gastrointestinal tract & 17 & 16 \\
Genitourinary & 14 & 4 \\
Musculoskeletal system & 6 & 4 \\
Cardiovascular system & 4 & 3 \\
Respiratory system & 1 & 2 \\
Special sensory as cleft lips and palate or anotia & 2 & 2 \\
Multiple sequences (syndromes) & 5 & \\
\hline
\end{tabular}

Table V: Possible etiology of gross congenital malformation in our study

1. Chromosomal anomalies

2. Environmental toxins as pesticides

3. Low socioeconomic status, overcrowding

4. Lack of education and awareness, antenatal patients not seeking clinics

5. Lack of nutrients as folic acid

\section{Discussion}

In the present study, the incidence of congenital anomalies is $2.03 \%$. In India incidence is more in the northern region as Punjab, Haryana, Rajasthan, Bihar (4). The incidence of congenital anomalies in India and eastern countries is quite variable ranging from $0.43 \%$ to $7 \%(5-8)$. While in western countries it is $2.4 \%$ and $2.9 / 1000$ live births $(9,10)$.

The incidence is more common in unbooked patients $(70 \%)$. It is like other studies by Sachdeva et al (5) where it was found to be $2.07 \%$ (unbooked) than $1.01 \%$ (booked). Unbooked patients are usually illiterate and of the low-income group and therefore unaware of the importance of antenatal care and folic acid. More than $50 \%$ of mothers of GCMF babies belonged to the rural background and have poor literacy and awareness and are mostly unbooked with no folic acid supplementation, indicating the underlying preventable cause of malformations especially neural tube defects (NTD). Malformations are more in multipara patients $(65.35 \%)$ as compared to primipara patients $(34.63 \%)$, this too is in concordance with the study by Hussain et al (8) where the incidence was $60.17 \%$ in multipara and $39.82 \%$ in primipara. This indicates that the incidence of congenital anomalies increases with birth order.

Congenital anomalies were more common in female babies in our study (1.17\%) as compared to male babies (1\%). This is comparable to a study done by Sachdeva et al i.e. female babies (2.14\%) account more than male babies (1.24\%). In contrast, malformations were found to be more common in male fetuses $(0.60 \%)$ than female fetuses $(0.25 \%)$ in a study by Gaur et al which is in concordance with the study done by Yorulmaz et al (11) male babies (52.2\%) outnumbered the female babies $(47.8 \%)(7,11)$. However, in our study, the overall incidence of malformation was high in female fetuses $(54 \%)$. The incidence of the genitourinary tract and cardiovascular defect was significantly higher in males whereas the incidence of NTD was higher in female fetuses but in other malformations, there was no significant difference.

In literature, most common birth defect reported in western countries is cardiovascular anomalies, corresponding to a study by Beksac MS in Ankara (10) but in India and eastern countries, most common congenital anomalies reported are neural tube defects. Twenty-nine percent of all neonatal deaths from congenital abnormalities are attributed to neural tube defects in South East Asia (12). Congenital malformations affect $2.5 \%$ of infants at birth and are responsible for about $15 \%$ perinatal mortality in India.

The fetal central nervous system (CNS) develops during the first trimester. NTD and CNS anomalies are the most common malformations of all congenital anomalies (13-18). Neural tube defects were found to be the most common congenital anomalies in this study too, accounting for $64 \%$ of total anomalies. Out of which hydrocephalus (Figure 1) and anencephaly were the commonest. It is comparable to a study by Yorulmaz et al in which hydrocephalus is most common (75.3\%) NTD (11). CNS anomalies top the list as depicted in the studies by Sachdeva et al (59.57\%) (5), Gaur et al $(41.09 \%)(7)$, Hussain et al $(20.35 \%)(5,7,8)$. NTD accounted for $52.3 \%$ of CNS anomalies and $16.5 \%$ of all anomalies in a study by Siddesh et al (19). 


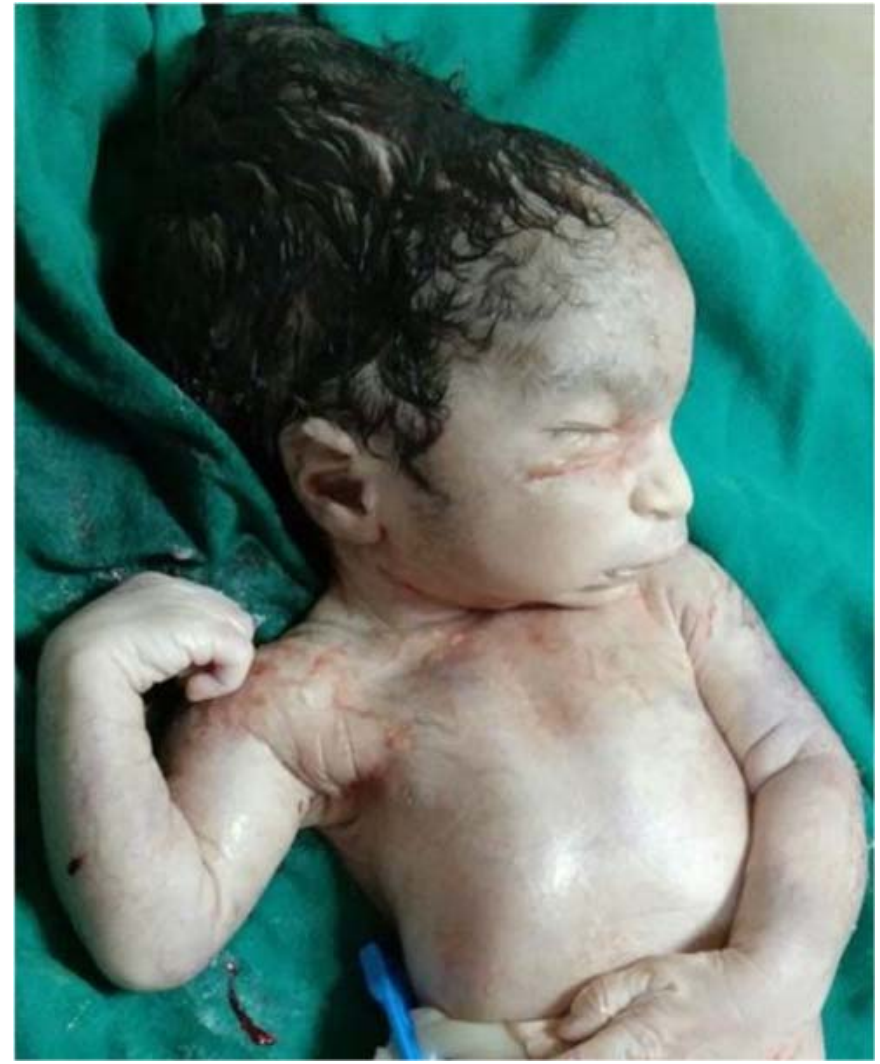

Figure 1: Hydrocephalic baby

In our study, $94.2 \%$ of the patients were delivered vaginally and only $5.7 \%$ underwent cesarean section. It contrasts with the study done by Sachdeva et al (5) in which cesarean rate $(4.36 \%)$ was more than vaginal deliveries $(0.62 \%)$. Most of the malformed babies were born in the third trimester.

Unfortunately, $18 \%$ of congenital anomalies remain undiagnosed until birth, while $81.5 \%$ anomalies were diagnosed antenatally by ultrasonography (79\%), fetal echo $(1.7 \%)$, and MRI $(0.8 \%)$.

Overall, babies with congenital anomaly had high perinatal mortality of $66 \%$. Multiple sequences of syndromes had the highest perinatal mortality rate of $100 \%$ followed by NTD which carries a $78 \%$ perinatal mortality rate. Best perinatal outcomes were with musculoskeletal defects.

The most common obstetric complication associated with congenital anomalies was polyhydramnios (14\%) followed by malpresentation in $9 \%$. Maternal diabetes was present in $2 \%$ cases, which is again a preventable cause of the birth defects. In mothers with diabetes, most common birth defect reported in the literature is cardiovascular system (CVS) defects, but in this study most common anomaly even in diabetic mothers was found to be NTD i.e., anencephaly. Oligohydramnios was present in 12 patients $(5 \%)$, postdated pregnancy in $5(2 \%)$, $\mathrm{Rh}$ isoimmunization in $4(1.7 \%)$, multifetal pregnancy in 4 $(1.7 \%)$ and maternal epilepsy in $1(0.4 \%)$ patient.

In conclusion, there is a need for increasing awareness about early detection of anomalies in the first-trimester scan and folic acid supplementation routinely in all females periconceptionally especially in the first three months of conception. A routine anomaly scan should be done at 18-20 weeks. Fetal echocardiography should be done at 22 weeks in all highrisk females e.g., those having diabetes or congenital heart disease or a family history of congenital heart disease. There is a need to take steps to optimize the health of pregnant women, for example, controlling the blood sugar of diabetic women well before conception and switch over to safer medication.

Wherever possible, a fetal autopsy should be done in all abortions, IUFD, and congenitally malformed babies incompatible to life. Before doing a cesarean section preferably malformations should be ruled out by sonography. One should be more vigilant if a cesarean section is being done for malpresentation or twin or associated with polyhydramnios or oligohydramnios. By proper antenatal care, we can decrease the incidence of congenital anomalies.

Acknowledgment: I want to thank the medical records department to give file records of patients.

Funding: There is no funding for this study.

Author contribution: VS:Data collection, S:Author, RM: Proof reading, PL:Editing, SS: Proof reading, and editing.

Conflict of interest: We declare that we have no conflict of interest.

\section{References}

1. Cunningham FG, Leveno K.J, Bloom SL, Dash JS, Hoffman BL, Cassey BM, Spong CY, editors. Williams Obstetrics (25 $5^{\text {th }}$ edition), Mc Graw Hill; 2017.p. 559.

2. Mathur SB, Mukherjee SB. Congenital malformations to birth defects - The Indian scenario. Indian Pediatr. 2017; 54(7):587-8. doi: 10.1007/s13312-017-1073-7.

3. WHO-Congenital anomalies factsheet updated September 2016. Available at: https://www.who.int/news-room/factsheets/detail/congenital-anomalies

4. Verma IC. Burden of genetic disorders in India. Indian J Pediatr. 2000;67(12):893-8. PMID: 11262988.

5. Sachdeva S, Nanda S, Bhalla K, Sachdeva R. Gross congenital malformation at birth in a government hospital. Indian J Public Health. 2014;58(1):54-6. doi: 10.4103/ 0019-557X.128170.

6. Shah K, Pensi CA. Study of incidence of congenital anomalies in new borns. Gujarat Medical J. 2013;68(2): 97-9.

7. Gaur S, Kataria SK, Raichandani L, Agarwal R, Joya HK. Study of incidence of congenital anomalies in newborns in western Rajasthan. Int J Appl Res. 2015;1(8):772-4.

8. Hussain S, Asghar I, Sabir MU, Chattha MN, Tarar SH, Mushtaq R. Prevalence and pattern of congenital malformations among neonates in the neonatal unit of a teaching 
hospital. J Pak Med Assoc. 2014;64(6):629-34. PMID: 25252479 .

9. Francine R, Pascale S, Aline H. Congenital anomalies: Prevalence and risk factors. Universal Journal of Public Health. 2014;2(2):58-63. doi: 10.13189/ujph.2014.020 204.

10. Beksac MS, Fadiloglu E, Unal C, Cetiner S, Tanacan A. 5 year experience of a tertiary center in major congenital abnormalities in singleton pregnancies. Birth Defects Res. 2020;112(8):633-9. doi: 10.1002/bdr2.1645.

11. Yorulmaz A, Konak M. Short term result of patients with neural tube defects followed-up in the Konya region, Turkey. Birth Defects Res. 2019;111(5):261-9. doi: 10. 1002/bdr2.1462.

12. Blencowe H, Cousens S. Modell B, Lawn J. Folic acid to reduce neonatal mortality from neural tube disorders. Int $\mathrm{J}$ Epidemiol. 2010;39(Suppl 1):110-121. doi: 10.1093/ije/ dyq028.

13. Sharma AK, Upreti M, Kamboj M, Mehra P, Das K, Misra A, et al. Incidence of neural tube defects of Lucknow over a 10 year period from 1982-1991. Indian J Med Res. 1994;99:223-6. PMID: 7927580.
14. Cherian A, Seena S, Bullock RK, Antony AC. Incidence of neural tube defects in the least-developed area of India: A population-based study. Lancet. 2005;366(9489):930-1. doi: 10.1016/S0140-6736(05)67319-9.

15. Duttachoudhury A, Pal SK. Congenital abnormalities in Durgapur Steel Plant Hospital with special reference to neural tube defect. J Indian Med Assoc. 1997;95(5):13541. PMID: 9357258.

16. Kulkarni ML, Mathew MA, Ramachandran B. High incidence of neural-tube defects in South India. Lancet. 1987; 1(8544):1260. doi: 10.1016/s0140-6736(87)92705-x.

17. Verma IC. High frequency of neural tube defects in North India. Lancet. 1978;1(8069):879-80. doi: 10.1016/s01406736(78)90225-8.

18. Babu RS, Pasula S. Frequency of foetal anomalies in a tertiary care centre. J Clin Diagn Res. 2013;7(7):1276-9. doi: 10.7860/JCDR/2013/6336.3187.

19. Siddesh A, Gupta G, Sharan R, Agarwal M, Phadke SR. Spectrum of prenatally detected central nervous system malformations: Neural tube defects continue to be the leading fetal malformation. Indian J Med Res. 2017 Apr;145(4):471-8. doi: 10.4103/ijmr.IJMR_1882_14. 